\title{
The Atmospheric Composition Validation and Evolution Workshop (ACVE2013) - Recommendations
}

\author{
Stefano Casadio ${ }^{1,2}$, Angelika Dehn ${ }^{1}$, Thorsten Fehr ${ }^{1}$, Bojan R. Bojkov ${ }^{1}$ \\ ${ }^{1}$ ESA-ESRIN, Frascati, Italy \\ ${ }^{2}$ SERCO-IDEAS, c/o ESA-ESRIN, Frascati, Italy
}

\section{INTRODUCTION}

$\mathrm{D}$ uring the last 18 years, the European Space Agency (ESA) has provided the scientific community with a large amount of valuable atmospheric composition data produced by a series of instruments, starting with GOME [Burrows et al. 1999], onboard the ERS-2 satellite (1995-2011), and followed by the GOMOS [Kyrola et al. 2004], MIPAS [Fischer et al. 2008], and the SCIAMACHY [Bovensmann et al. 1999], all flying on-board the Envisat satellite (20022012). These observations will be continued by the Sentinel-5 Precursor, Sentinel-4 and Sentinel-5 and extended the EarthCARE and ADM missions for aerosols and clouds.

The quality assessment of atmospheric parameters retrieved from ESA satellite instruments has been, and continues to be, performed through the joint effort of the scientific community and ESA. The calibration and validation of atmospheric products (Cal/Val), for both measured radiances (Level-1) and retrieved atmospheric parameters (Level-2), is a continuous process that starts well before the launch of the satellite, and continues after the decommissioning of the platform. In this context, a large number of activities are promoted by ESA with the support of the Mission Advisory Groups (MAGs) during the pre-launch phases of the missions, and the Quality Working Groups (QWGs) during the post-launch phases of the missions.

The knowledge gained by ESA's Cal/Val activities is made publicly accessible to the at- mospheric community through scientific and technical publications, as well as through a series of dedicated workshops and conferences sponsored by ESA. The series of workshops dedicated to the $\mathrm{Cal} / \mathrm{Val}$ of atmospheric products started with the "Pre-launch Workshop on the Atmospheric Chemistry Validation of Envisat (ACVE)" in 2001 [ACVE 2001], followed by the "ENVISAT Validation Workshop" in 2002 [Envisat Validation 2002]. Two years afterwards, in 2004, ESA organised the second "Atmospheric Chemistry Validation of Envisat (ACVE- 2) [ACVE-2 2004], followed by the third "Atmospheric Chemistry Validation of Envisat (ACVE- 3)" in 2006 [ACVE-3 2006]. After each Cal/Val workshop, ESA was provided by the participants with a comprehensive list of comments, suggestions and recommendations, critical for the successful operations of ESA missions [Snoeij et al. 2004, Snoeij et al. 2007]. Cal/Val recommendations are also provided to ESA in occasion of conferences with broader scopes. An important and recent example is represented by the ATMOS conference, organised by ESA and held in Bruges (Belgium) on 18-22 June 2012 [ATMOS2012]. In particular, the recommendations regarding spectroscopy studies, the reprocessing capabilities, and the maintenance/enhancement of the validation infrastructure are important contributions to the $\mathrm{Cal} / \mathrm{Val}$ activities. Apart from specific recommendations to the ERS-2 and ENVISAT missions, a number of general considerations were raised during past ACVEs. The most relevant recommendations are summarised below: 
- Improve communication between Level-1 and Level-2 development teams;

- Provide information about data processor changes to users in a transparent way;

- Document and announce well in advance (whenever possible) all changes in processors, algorithms and initialisation files;

- Product user manuals should be well written, including detailed format and content description;

- Auxiliary files should be available and documented;

- A well-defined validation reference set should be processed completely after each processor upgrade and analysed before reprocessing the complete mission.

These recommendations have all been fulfilled by ESA during the ENVISAT mission lifetime, and are now guidelines for future missions.

In March 2013, ESA organised the "Atmospheric Composition Validation and Evolution (ACVE2013)" [ACVE 2013] workshop with a much wider scope including: 1) Future Missions and Evolution [e.g., Castelli et al. 2013]; 2) Instrument Calibration and Level-1 products; 3) Methods and Instruments for Validation [e.g., Garcia et al. 2013]; 4) Algorithms and Products [e.g., Raspollini et al. 2013]; 5) Ozone [e.g., Waymark et al. 2013]; 6) CO, CO2 and CH4 [e.g., Del Bianco et al. 2013]; 7) Minor Trace Gases [e.g., Papandrea et al. 2013]; 8) Clouds, Aerosols and Water Vapour; 9) Methods and Instruments for Thermodynamic Variables. Scientists and Cal/Val experts have been provided with the opportunity to present latest results from their on-going research, including the evolution of algorithms and new validation methods, not restricted to ESA missions. 125 participants from 14 countries were registered with the large majority from ESA member states and a significant participation from the USA and Canada.

A set of recommendations for the evolution of the ESA's activities, resulting from the workshop discussions, are reported in the next paragraphs. The recommendations have been grouped in the following seven categories: Calibration and Level-1 products, Spectros- copy, Product Development/ Evolution, Algorithms and Products Review Process, Validation Infrastructure, Data Utilisation, and Evolution of Validation Needs. ESA will carefully assess and prioritise the ACVE2013 recommendations, noting that a number of recommendations are already being addressed or are planned to be considered in the near future.

In the next paragraphs, recommendations are identified with the ' $[\operatorname{Rec} X]^{\prime}$ label, where $X$ is an identification number with no reference to any priority ranking.

\section{Calibration and Level-1}

Important considerations on pre-flight activities have been raised. Firstly, it was recommended to focus during the development phase on intensive instrument on-ground calibration activities, along with the provision of the related detailed documentation and the maintenance of the instrument models [Rec1]. Secondly, it was stressed that the end-to-end performance tests of the complete data processing system should be accomplished well before the satellite launch [Rec2].

\section{Spectroscopy}

Spectroscopy plays a fundamental role in the atmospheric remote sensing and the necessity of establishing a consistent spectral database is evident [Rec3]. In particular, there is a strong need for support to the development of a homogenous Ozone cross-section dataset across wavelength ranges [Rec4]. In addition to Ozone, supporting new spectroscopy activities on water vapour and methane in the SWIR (Short Wave Infra-Red) range, impacting the $\mathrm{CO}$ retrievals around $2.3 \mu \mathrm{m}$, have been recommended [Rec5].

\section{Product Development and Evolution}

Establishing a program for new satellite products is needed, if possible coordinated among ESA, the European Commission (EC) and the national space/funding agencies [Rec6]. ESA should continue to coordinate the product developments of Sentinel-5p (S5p), Sentinel-4 (S4) and Sentinel-5 (S5) [Rec7], taking into account the individual performances of the different instruments. For future developments, a special focus needs to be on the absorption 
cross-sections used in the retrievals for the interpretation of differences between products [Rec8] and multi-missions calibration aspects. As follow on activity to the ACVE, ESA organised an inter-instrument workshop the "EO Level-1 lessons learned" in June 2013 covering degradation and pointing aspects. A specific recommendation from this workshop is to create a Level-1 Quality Working Group (QWG) across instrument families to enhance the information and analysis exchange. The necessity to create a priority list for the Level- $1 b$ evolution tasks, as identified by the instrument QWGs, as well as to make it available to the science community for comments and suggestions [Rec9] was recognised. The need to establish new mission performance criteria for existing products (e.g. ENVISAT, ERS-2) has been identified. These new criteria should be superseding pre-launch requirements, based on evolving user requirements and scientific developments, and should be used for prioritizing evolution activities [Rec10]. This could be achieved by redefining the performance criteria for products through the revision of existing requirements as a joint effort from ESA, QWGs and the user communities. In order to optimise the verification and validation process of new Envisat/ERS product releases, well defined verification and validation datasets need to be provided to the $\mathrm{Cal} / \mathrm{Val}$ community [Rec11]. In addition to the QWGs, it should also involve teams outside ESA funded projects, i.e. through national and international activities. This activity would facilitate the establishment of a joint cycle for reprocessing and re-analysis within the atmospheric composition community [Rec12].

Algorithms and Products Review Process

The ACVE2013 community recommends the establishment of a review process for evolution new algorithms and new mission activities [Rec13].

\section{Validation Infrastructure}

An essential aspect for future ESA Cal/Val activities consists in securing the existing Cal/Val infrastructure and establishing an entity taking over the ownership and the respon- sibility [Rec14]. In parallel, new developments in validation infrastructure should be supported. In particular, the improvement of airborne MAX-DOAS systems [Rec15], the creation of Total Carbon Column Observing Network (TCCON) [Toon et al. 2009] sites characterised by different illumination/albedo conditions [Rec16]. The use of mini-spectrometer instruments in the Network for the Detection of Atmospheric Composition Change (NDAAC) [Rec17] shall be facilitated by providing support to the development and operation of instruments targeting Air Quality (AQ). Further investigating options to support "mini-interferometer" developments and operations for high-precision greenhouse gas measurements were addressed. This should be done in conjunction with the implementation of systems supporting the validation of minor trace gases (e.g. $\mathrm{HCHO}, \mathrm{BrO}, \mathrm{OClO}$ ) and of tropospheric Ozone [Rec18]. The identification of reference validation sites for both past and future ESA missions [Rec19] should be addressed by revisiting the reference site concept with CEOS and CVI for atmospheric composition and specifically air quality (AQ) validation. In addition to $\mathrm{AQ}$ instrumentation, the support to stratospheric balloon "anchor" measurements in the post-limb sounding era is essential in order to address the Montreal protocol to understand the trends in the stratosphere, as well as for the assessment of the remaining limb observation systems [Rec20]. ESA cooperation and coordination with national environmental agencies and the European Environment Agency (EEA, http: / / www.eea.europa.eu/) for satellite validation [Rec21] shall be undertaken. The need to establish a legal framework for air quality monitoring that goes beyond the current regulations was also highlighted. This would require more sophisticated measurement protocols and instrumentation that can also be used for satellite validation [Rec22]. A web portal covering ESA and non-ESA atmospheric validation activities, offering links to $\mathrm{Cal} / \mathrm{Val}$ information and datasets, and allowing for the direct involvement of the international scien- 
tific community should be implemented, establishing links with non-ESA Cal/Val teams, in particular regarding infrastructure [Rec23].

\section{Evolution of Validation Needs}

A clear need to develop validation activities for AQ products in "challenging" conditions has been identified during the ACVE2013 to be documented in an "Air Quality Validation Plan". In particular, areas with strong pollution gradients, different cloud conditions, variable terrain types and slopes, and high aerosol loads should be considered for the installation of validation tools [Rec24] [see e.g. Richter et al. 2013]. In addition, the validation of background profile information, used in nadir retrievals and relative to the challenging conditions indicated above, is also required [Rec25]. As a result the need to establish ground based instrument networks in polluted areas [Rec26] was highlighted. It is recommended that ESA facilitates and co-organises validation campaigns with a focus on AQ satellite product challenges. Support for the development and operation of instrument developments targeting AQ (e.g., mini-spectrometers [Tzortziou et al. 2012], AirCORE [Karion et al. 2010]) and the implementation of a European minispectrometer/MAXDOAS network is needed.

The necessity for the improvement of an effective characterisation of observation errors for satellite and correlative validation datasets has been identified [Rec28].

\section{Data Utilisation}

Satellite data distribution is the core activity for a Space Agency, and improvements in this context are fundamental for the success of any satellite mission. The ACVE2013 community recommends to establish a "data product utilization advisory group" that should provide ESA with feedback and advise on data accessibility and on prioritisation of developments [Rec29]. A pressing need highlighted during the workshop is the harmonisation of the data format for all specific instruments, possibly adopting an established, selfdescribing, easy readable format [Rec30]. This could be achieved by providing all operational ESA atmospheric composition products in community accepted formats such as netCDF-4 with the netCDF Climate and Forecast (CF) Metadata Convention (http: / / cf-pcmdi.llnl. gov/). On the data dissemination, a coordinated access to ESA, European and national data centres is urgently needed [Rec31]. Generally users need to have easy access to data, avoiding complicated registration procedures. [Rec32].

\section{Conclusions}

The ACVE2013 provided an important and valuable forum for $\mathrm{Cal} / \mathrm{Val}$ and algorithm scientists to present and discuss their results with the atmospheric composition satellite remote sensing community. In addition, it gave the opportunity to highlight and discuss a broad range of issues related to the satellite missions directly with ESA. On the ESA side, the intense exchange with the expert users is of highest priority to identify problems and to find opportunities to resolve them with the recommendations by the community, as well as to prepare future developments.

ESA will carefully assess and prioritise the recommendations and defining activities accordingly. A number of recommendations are already being addressed, e.g., first steps to a Level 1b Working Group have been implemented, the existing CEOS Cal/Val portal is being extended to cover atmospheric composition and a number of system developments are on-going or under preparation.

The mission end-to-end data quality improvement and evaluation loop is a process open to the community. Several mechanisms are already in place, e.g., the ESA Helpdesk, QWGs and workshops. In the near future, ESA is committed to facilitate direct contacts between Cal/Val entities, through regular ACVE workshops in the coming years.

\section{References}

ACVE (2001). Pre-launch Workshop on the Atmospheric Chemistry Validation of Envisat (ACVE), 16-18 May 2001, ESTEC, The Netherlands,

http:/ / esamultimedia.esa.int/ conferences / 01 C13/index.html. 
ACVE-2 (2004). Atmospheric Chemistry Validation of Envisat (ACVE- 2), 3-7 May 2004, ESA-ESRIN, Frascati, Italy, http:/ / earth.esa.int/envisat/workshops/acve $2 /$ presentations/.

ACVE-3 (2006). Atmospheric Chemistry Validation of Envisat (ACVE- 3), 4-7 December 2006, ESA-ESRIN Frascati, Italy, http:/ / earth.esa.int/workshops/acve3/.

ACVE2013 (2013). Atmospheric Composition Validation and Evolution (ACVE2013) workshop, 13-15 March 2013, ESA-ESRIN, Frascati, Italy, http:/ / congrexprojects.com/2013events/acve2013/introduction.

ATMOS2012, 'ATMOS 2012 Conference - Advances in Atmospheric Sciences and Applications: Session Summaries and Recommendations', EOEP-DTEX-EOPS-RD-12-0002, http: / / congrexprojects.com/2012events/atmos2012/recommendations.

Bovensmann, H., J. P. Burows, M. Buchwitz, J. Frerick, S. Noel and V. V. Rozanov (1999). SCIAMACHY: Mission Objectives and Measurement Modes, Journal of the Atmospheric Sciences, 56, 2, 127-150.

Burrows, J.P., M. Weber, M. Buchwitz, V. Rozanov, A. Ladstatter-Weissemayer, A. Richter, R. DeBeek, R. Hoogen, K. Bramstedt, K-U Eichmann and M. Eisinger (1999). The Global Ozone Monitoring Experiment (GOME): Mission Concepr and First Scientific Results, J. Atmos. Sci., 56, 151-175.

Castelli, E., S. Del Bianco, B.M. Dinelli, D. Gerber, H. Oelhaf, W. Woiwode, B. Vogel, B-M. Sinnhuber, R. Ruhnke and U. Cortesi (2013). Results of the preparatory study "PREMIER Analysis of Campaign Data", Annals of Geophysics, 56, Fast Track 1, 2013; 10.4401/ag-6333.

Del Bianco, S., B. Carli, M. Gai, L. M. Laurenza and U. Cortesi (2013). XCO2 retrieved from
IASI using KLIMA algorithm, Annals of Geophysics, 56, Fast Track 1, 2013; 10.4401/ag-6331.

Fischer, H., M. Birk, C. Blom, B. Carli, M. Carlotti, T. von Clarmann, L. Delbouille, A. Dudhia, D. Ehhalt, M. Endemann, J. M. Flaud, R. Gessner, A. Kleinert, R. Koopman, J. Langen, M. L'opez-Puertas, P. Mosner, H. Nett, H. Oelhaf, G. Perron, J. Remedios, M. Ridolfi, G. Stiller and R. Zander (2008). MIPAS: an instrument for atmospheric and climate research, Atmos. Chem. Phys., 8, 2151-2188, www.atmos-chem-phys.net/8/2151/2008/.

Omaira, G., M. Schneider, F. Hase, T. Blumenstock, A. Wiegele, E. Sepúlveda and A. Gómez-Peláez (2013). Validation of the IASI operational $\mathrm{CH} 4$ and $\mathrm{N} 2 \mathrm{O}$ products using ground-based Fourier Transform Spectrometer: preliminary results at the Izaña Observatory $\left(28^{\circ} \mathrm{N}, 17^{\circ} \mathrm{W}\right)$, Annals of Geophysics, 56, Fast Track 1, 2013; 10.4401/ag-6326.

Honninger, G., C. von Friedeburg and U. Platt (2004). Multi axis differential optical absorption spectroscopy (MAX-DOAS), Atmos. Chem. Phys., 4, 231-254, www.atmos-chemphys.org/acp/4/231/.

Karion, A., C. Sweeney, P. Tans and T. Newberger (2010). AirCore: An Innovative Atmospheric Sampling System, J. Atmos. Ocean Tech., 27, 1839-1853, doi: 10.1175/2010JTECHA1448.1, http:/ / www.esrl.noaa.gov/gmd/ccgg/aircraf t/ aircore.html.

Kyrola, E., J. Tamminen, G.W. Leppelmeier, V. Sofieva, S. Hassinen, J.L. Bertaux, A. Hauchecorne, F. Dalaudier, C. Cot, O. Korablev, O. Fanton d'Andon, G. Barrot, A. Mangin, B. Theodore, M. Guirlet, F. Etanchaud, P. Snoeij, R. Koopman, L. Saavedra, R. Fraisse, D. Fussen and F. Vanhellemont (2004). GOMOS on Envisat: an overview, Advances in Space Research, 33, 10201028, doi:10.1016/S0273-1177(03)00590-8.

Papandrea, E., S. Casadio, E. Arnone, M. Carlotti, E. Castelli, M. De Laurentis, B. M. Dinelli 
(2013). Validation of minor species of the MIPAS2D database, Annals of Geophysics, 56, Fast Track 1, 2013; 10.4401/ AG-6332.

Raspollini, P., E. Arnone, F. Barbara, B. Carli, E. Castelli, S. Ceccherini, B. M. Dinelli, A. Dudhia, M. Kiefer, E. Papandrea, M. Ridolfi (2013). Comparison of the MIPAS products obtained by four different level 2 processors, Annals of Geophysics, 56, Fast Track 1, 2013; 10.4401/ag6338.

Rothman, L.S., I.E. Gordon, A. Barbe, D.C. Benner, P.F. Bernath, M. Birk, V. Boudon, L.R. Brown, A. Campargue, J.-P. Champion, K. Chance, L.H. Coudert, V. Danaj, V.M. Devi, S. Fally, J.-M. Flaud, R.R. Gamache, A. Goldmanm, D. Jacquemart, I. Kleiner, N. Lacome, W.J. Lafferty, J.-Y. Mandin, S.T. Massie, S.N. Mikhailenko, C.E. Miller, N. MoazzenAhmadi, O.V. Naumenko, A.V. Nikitin, J. Orphal, V.I. Perevalov, A. Perrin, A. PredoiCross, C.P. Rinsland, M. Rotger, M. Simeckova, M.A.H. Smith, K. Sung, S.A. Tashkun, J. Tennyson, R.A. Toth, A.C. Vandaele and J. VanderAuwera (2008). The HITRAN 2008 molecular spectroscopic database, Journal of Quantitative Spectroscopy \& Radiative Transfer, 110, 533-572, doi:10.1016/j.jqsrt.2009.02.013.

Snoeij, P., P. Fletcher, R. Koopman, P. Wursteisen, T. Wehr, C. Zehner and E. Attema (2007). Summary of the Atmospheric Chemistry Instrument, Proceedings of the Second Workshop on the Atmospheric Chemistry Validation of Envisat (ACVE-2), 3-7 May 2004, ESRIN, Frascati, Italy, https: / / earth.esa.int/ workshops / acve2/ conte nts.html.

Snoeij, P., A. Piters, H. Fischer, Y. Meijer, J-C Lambert and T. Fehr (2007). Summary of the Atmospheric Chemistry Instrument Validation Results as presented at the ACVE-3 Workshop, Proceedings of the Third Workshop on the Atmospheric Chemistry Validation of Envisat (ACVE-3), 4-7 December 2006, ESRIN, Frascati, Italy (ESA SP-642, February2007), https: / / earth.esa.int/ web / guest / - thirdworkshop-on-the-atmospheric-chemistryvalidation-of-envisat-acve-3-5161.

Toon, G., J. Blavier, R. Washenfelder, D. Wunch, G. Keppel-Aleks, P. Wennberg, B. Connor, V. Sherlock, D. Griffith, N. Deutscher and J. Notholt (2009). Total Column Carbon Observing Network (TCCON), In: Advances in Imaging, OSA Technical Digest (CD) (Optical Society of America, 2009), paper JMA3, http:/ / www.opticsinfobase.org/abstract.cfm? URI=FTS-2009-JMA3.

Tzortziou, M., J. R. Herman, A. Cede and N. Abuhassan (2012). High precision, absolute total column ozone measurements from the Pandora spectrometer system: Comparisons with data from a Brewer double monochromator and Aura OMI, J. Geophys. Res., 117, D16303, doi:10.1029/2012JD017814.

Waters, J. W., L. Froidevaux, R. S. Harwood, R. F. Jarnot, H. M. Pickett, W. G. Read, P. H. Siegel, R. E. Cofield, M. J. Filipiak, D. A. Flower, J. R. Holden, G. K. Lau, N. J. Livesey, G. L. Manney, H. C. Pumphrey, M. L. Santee, D. L. Wu, D. T. Cuddy, R. R. Lay, M. S. Loo, V. S. Perun, M. J. Schwartz, P. C. Stek, R. P. Thurstans, M. A. Boyles, K. M. Chandra, M. C. Chavez, G-S Chen, B. V. Chudasama, R. Dodge, R. A. Fuller, M. A. Girard, J. H. Jiang, Y. Jiang, B. W. Knosp, R. C. LaBelle, J. C. Lam, K. A. Lee, D. Miller, J. E. Oswald, N. C. Patel, D. M. Pukala, O. Quintero, D. M. Scaff, W. Van Snyder, M. C. Tope, P. A. Wagner and M. J. Walch (2006). The Earth Observing System Microwave Limb Sounder (EOS MLS) on the Aura Satellite, IEEE Transactions on Geoscience and Remote Sensing, 44, 5, 1075-1091.

Waymark, C., K. Walker, C. D. Boone and P. F. Bernath (2013). ACE-FTS version 3.0 data set: validation and data processing update, Annals of Geophysics, 56, Fast Track 1, 2013; 10.4401 / ag-6339. 